\title{
Homologous recombination in the tandem calmodulin genes of Trypanosoma brucei yields multiple products: compensation for deleterious deletions by gene amplification
}

\author{
Josiane E. Eid and Barbara Sollner-Webb \\ Department of Biological Chemistry, The Johns Hopkins University School of Medicine, Baltimore, Maryland 21205 USA
}

\begin{abstract}
Homologous recombination between a calmodulin-neomycin-resistance fusion gene and the Trypanosoma brucei chromosome takes place not only in the large $5^{\prime}$ - and $3^{\prime}$-flanking segments of the calmodulin locus but also in any of the four tandem genomic calmodulin genes. This results in a recombined locus consisting of the chimeric neo ${ }^{\mathrm{x}}$ gene and four, three, two, one, or zero functional calmodulin genes. Cells bearing this latter event have half of their normal number of intact calmodulin genes and an accompanying phenotype of slow growth. Over months of propagation, these lines acquire additional calmodulin genes, frequently by amplifying a calmodulin gene at the untargeted locus, and concomitantly revert to normal growth rate. This response could be related to the property of the trypanosome of maintaining most housekeeping genes in tandem chromosomal arrays. Recombination appears to be initiated by a crossover event between the linearized end of the transfecting plasmid and a homologous region in the host genome; the second crossover generally occurs internally and in that region requires no more than $87 \mathrm{bp}$ of homology.
\end{abstract}

[Key Words: Homologous recombination; calmodulin genes; Trypanosoma brucei; gene amplification]

Received July 11, 1991; revised version accepted September 4, 1991.

Our laboratory and others have reported that stable transformation of Trypanosoma brucei and related organisms appears to occur by integration of the exogenous DNA into the homologous chromosomal locus /Cruz and Beverly 1990; Lee and Van der Ploeg 1990; Ten Ashroek et al. 1990; Eid and Sollner-Webb 1991). The other laboratories studying $T$. brucei used plasmids singly cut within a tubulin gene region; five resultant stably transformed cell lines were analyzed, and these had up to 16 copies of the entire plasmid integrated into the endogenous tubulin locus (Lee and Van der Ploeg 1990; Ten Ashroek et al. 1990). Our system (Eid and Sollner-Webb 1991) utilized an excised calmodulin-neomycin-resistance fusion gene ( $\mathrm{CNeoC})$, and seven resultant stable cell lines all showed targeting of a single copy of the transfecting DNA to the calmodulin locus. In this paper we demonstrate that this targeting event involves homologous recombination and is accurate to the nucleotide. Characterization of the 5 '- and 3 '-recombination products from 33 transfected cell lines showed that the $\mathrm{CNeoC}$ sequences targeted to the genomic calmodulin locus in all cases. By using doubly digested plasmids, recombination events were found to occur both in large terminal regions of calmodulin locus homology and in any of the four tandem genomic calmodulin gene re- peats. This results in deletion of one, two, three, or all four of the calmodulin genes in the targeted locus. Plasmids linearized within a region of homology also yielded transformants in which the entire plasmid had inserted into the calmodulin locus without accompanying loss of chromosomal sequences. Interestingly, resultant cell lines that contain only the four intact calmodulin genes of the unrecombined chromosomal locus exhibited impaired growth. Over time, these cell lines reverted to normal growth rate and, in concert, acquired an additional calmodulin gene copy, frequently by duplicating one of their remaining calmodulin genes.

\section{Results}

Homologous integration of $\mathrm{CNeOC}$ involves recombination with various segments of the tandem calmodulin locus

We have reported stable transformation of the procyclic form of $T$. brucei using the chimeric CNeoC DNA (Fig. 1A) cleaved with $X b a I$ and NotI to remove vector sequences (Eid and Sollner-Webb 1991). This construct contains the neomycin resistance $\left(\right.$ neo $^{\mathrm{r}}$ )-coding region inserted, in-frame, within a complete $T$. brucei calmod- 
A.

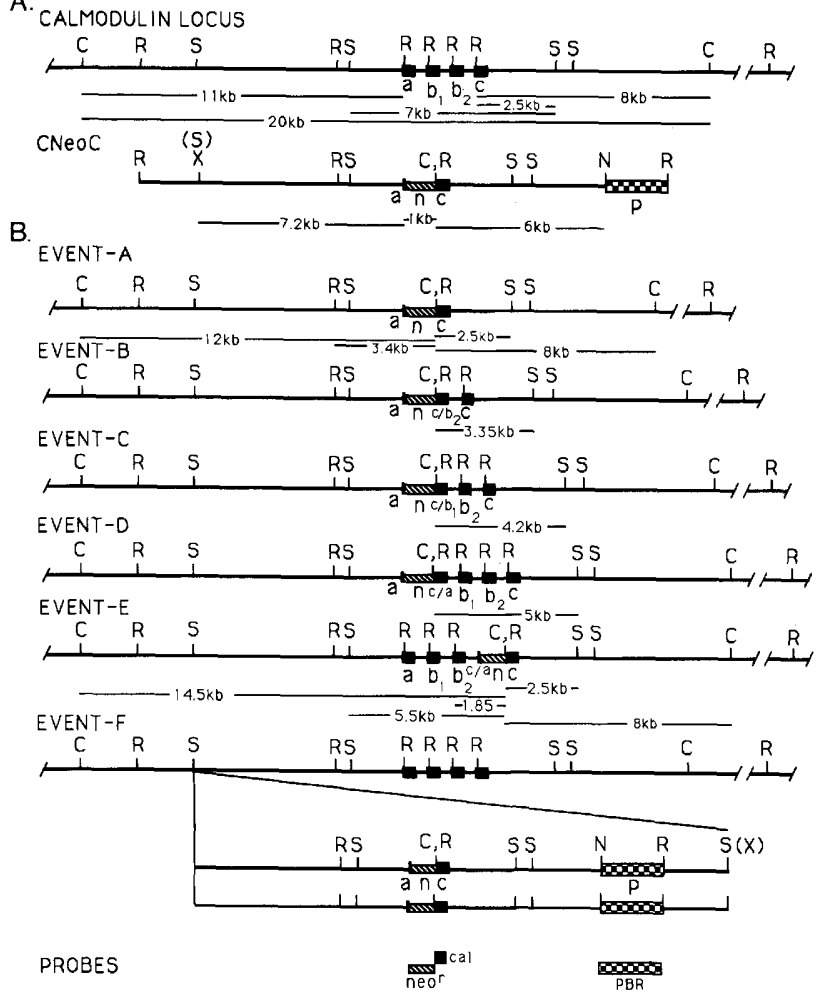

Figure 1. The products of recombination of plasmid $\mathrm{CNeoC}$ and the calmodulin locus. (A) The organization of the endogenous $T$. brucei calmodulin locus (Tschudi et al. 1985; Eid and Sollner-Webb 1991) and the CNeoC plasmid (Eid and SollnerWebb 1991) is depicted in the top two lines. The solid box represents the calmodulin-coding regions. (The calmodulin gene repeat is $0.85 \mathrm{~kb}$, and the $5^{\prime}$ - and $3^{\prime}$-flanking EcoRI fragments are 2.4 and $12 \mathrm{~kb}$, respectively.)(B) Events A-E, diagramed below, are the products of double crossovers. In event $A$, one crossover occurred in the $7.2 \mathrm{~kb}$ of homology $5^{\prime}$ to the $n e o^{\mathrm{x}}$ sequence, and the other in the $6 \mathrm{~kb}$ of homology $3^{\prime}$ to the neor sequence. In events $\mathrm{B}-\mathrm{D}$, the first crossover occurred in the $7.2 \mathrm{~kb}$ of $5^{\prime}$. flanking homology and the second in the $420 \mathrm{bp}$ of homology with calmodulin genes $b_{2}, b_{1}$, and $c$, respectively. In event $\mathrm{E}$, the first crossover occurred in the $6 \mathrm{~kb}$ of 3 -flanking homology and the second in the 87-bp homologous segment flanking the translation initiation site of the $c$ gene. Event $F$ represents homologous insertion of two entire copies of plasmid $\mathrm{CNeoC}$ in the $5^{\prime}$ region of the calmodulin locus. Probes $n e o^{\mathrm{r}}$, cal, and $\mathrm{pBR}$ are illustrated below. (C) ClaI; (R) EcoRI; (S) SalI; (X) XbaI; (N) NotI; $(\mathrm{X})$ mutated site. Parentheses denote mutated sites.

ulin gene and is flanked by $7.2 \mathrm{~kb}$ of upstream and $6 \mathrm{~kb}$ of downstream sequence of the calmodulin locus (Fig. 1A, line 2). Analysis of seven resultant cell lines by Southern blotting of ClaI-, BglII-, or EcoRI-digested genomic DNA and by pulsed-field gel electrophoresis had indicated that the transfecting CNeoC DNA targeted to the calmodulin locus and that the upstream recombination event had occurred within the 7.2-kb $5^{\prime}$-flanking region in all these lines (Eid and Sollner-Webb 1991). We had not specifically identified the downstream recombination event, although one might have suspected that it would occur within the $6 \mathrm{~kb}$ of $3^{\prime}$-flanking region. However, the calmodulin-coding sequence is repeated four times at both chromosomal calmodulin loci in the recipient $T$. brucei strain $\left(a, b_{1}, b_{2}\right.$, and $c$ genes $)$, and most of this sequence is located just downstream of the neor sequences in $\mathrm{CNeoC}$ (Fig. 1A), so the downstream recombination event could also involve these homologous gene segments. Thus, we wanted to analyze the products of the targeted integration of CNeoC DNA into the trypanosome genome to determine in which regions of the calmodulin locus the downstream recombination occurred, to confirm that homologous recombination was responsible for the gene targeting, and to ascertain whether gene insertions in addition to gene replacements occurred when the transfecting DNA was singly cleaved within a region of homology.

Procyclic trypanosomes were transfected by using CNeoC DNA cleaved with $X b a I$ within the 5 -flanking calmodulin region, with NotI at the end of the $3^{\prime}$-flanking calmodulin region, or with both $\mathrm{XbaI}$ and NotI (see Fig. 1A). Thirty-three resultant cell lines, derived from two to three separate electroporation experiments for each differently cleaved DNA, were selected by growth in the presence of G418 and were cloned by dilution. Their genomic DNA was restricted and analyzed by using probes for the neomycin-resistance $\left(\mathrm{neo}^{\mathrm{r}}\right)$, calmodulin (cal), and pBR322 vector (pBR) regions, sequentially (diagramed at the bottom of Fig. 1). In all cases, the $\mathrm{CNeoC}$ sequences targeted to the genomic calmodulin cluster. However, the structure of the resultant cellular DNA was not identical but fell into six distinct classes, events A-F (diagramed in Fig. 1B; the cell lines constituting each event are listed in Table 1). Data for representative members of each are presented in Figures 2 and 5 (below) as indicated: ClaI-cut DNA, neo ${ }^{\mathrm{r}}$ probe (Fig. 2A); ClaI-cut DNA, cal probe (Fig. 2B); EcoRI-cut DNA, neo probe (Fig. 2C); ClaI- and SalI-cut DNA, cal probe (Fig. 5); additional analyses (not shown).

Initial evidence that all transformants were not identical came from Southern analysis of genomic DNA digested with ClaI, which cleaves at the $3^{\prime}$ border of the neo ${ }^{\mathrm{r}}$ sequence in the chimeric $\mathrm{CNeoC}$ construct (Fig. 1A). When probed for neo sequences, most cell lines yielded a 12-kb fragment (events A-D; Fig. 2A; Table 1), indicating that the upstream recombination occurred within the $7.2 \mathrm{~kb}$ of $5^{\prime}$ homology between $\mathrm{CNeoC}$ plasmid and genomic DNA (Fig. 1A; for details, see Eid and Sollner-Webb 1991). However, the ClaI-cleaved DNA from a few lines yielded $n e \mathrm{O}^{\mathrm{r}}$-containing fragments of two other sizes (Fig. 2A), either $14.5 \mathrm{~kb}$ (event E) or $\sim 18$ $\mathrm{kb}$ plus $12 \mathrm{~kb}$ (event $\mathrm{F}$ ), as described below, whereas control untransformed cells showed no hybridizing material (Fig. 2A, lane Co). Thus, transformation with $\mathrm{CNeoC}$ DNA yields at least three different recombination products.

\section{Cell lines of events $A-D$}

When the filter of Figure 2A was stripped and reprobed by using the calmodulin-coding region (diagramed in Fig. 
Table 1. Cells lines corresponding to the various recombination events obtained with differently cleaved CNeoC DNA

\begin{tabular}{|c|c|c|c|c|}
\hline \multirow[b]{2}{*}{ Event } & \multirow{2}{*}{$\begin{array}{c}\text { Replaced } \\
\text { calmodulin genes }\end{array}$} & \multicolumn{3}{|c|}{$\begin{array}{l}\text { Cell lines derived from transfected } \\
\text { CNeoC DNA cleaved with }\end{array}$} \\
\hline & & $X b a \mathrm{I}+$ NotI & $X b a I$ & NotI \\
\hline A & $a b_{1} b_{2} c$ & - & $5,6,7,9,21$ & $\mathrm{R}, \mathrm{Z}$ \\
\hline B & $a b_{1} b_{2}$ & $\mathrm{r}$ & - & - \\
\hline $\mathrm{C}$ & $a b_{1}$ & $a, b, d, e, f$ & 8,10 & - \\
\hline $\mathrm{D}$ & $a$ & $\mathrm{k}$ & $17,18,20$ & - \\
\hline $\mathrm{E}$ & $c$ & $\mathrm{~m}$ & - & l, i, h, t, E \\
\hline $\mathrm{F}$ & insertion & - & 2,11 & - \\
\hline
\end{tabular}

All the cell lines of event A changed upon continued propagation. It is unlikely that event A was greatly under-represented in our original collection of clones as a result of growth rate selection, because the characterized secondary mutations occurred slowly, over a period of several months. Lines 21 and $\mathrm{R}$ acquired an additional calmodulin gene copy at the untargeted calmodulin locus.

1B), six different patterns were observed (Fig. 2B). All of the cell lines, like the control untransfected cells (Fig. 2B, lane Col, gave a 20-kb calmodulin-containing ClaI fragment. Thus, this fragment represents the unrecombined calmodulin locus. All of the transfected cells yielded additional calmodulin-containing fragments. Most lines showed one such fragment, which contains the DNA sequences extending downstream from the ClaI site of the integrated CNeoC DNA (Fig. 1B). This fragment falls into four different length classes (Fig. 2B, events $\mathrm{A}-\mathrm{D}$ ). The smallest is $8 \mathrm{~kb}$, the size expected when the downstream recombination event took place within the $6 \mathrm{~kb}$ of $3^{\prime}$ homologous flanking DNA (event A). Accordingly, this ClaI fragment comigrates with the analogous fragment excised from the untransfected cellular DNA by EcoRI and ClaI digestion (see Fig. 1A,B; data not shown). Thus, in the cell lines of event $A$ the four tandem genomic calmodulin-coding regions have been replaced by the $\mathrm{CNeoC}$ fusion gene.

The analogous fragments from the cell lines of events A, B, C, and D differ in size by units of $\sim 0.85 \mathrm{~kb}$ (Fig. 2B). Because the tandem chromosomal calmodulin genes $a$, $b_{1}, b_{2}$, and $c$ form a $0.85-\mathrm{kb}$ repeat (Tschudi et al. 1985; see Fig. 1A), the successively larger fragments evidently represent cell lines retaining one, two, or three of the chromosomal calmodulin genes downstream of the $\mathrm{CNeoC}$ region (Fig. 1B, events $\mathrm{B}-\mathrm{D}$ ). These transformants presumably arose from a recombination event between the $420 \mathrm{bp}$ of the common calmodulin-coding region present downstream of the neor sequences in $\mathrm{CNeoC}$ and the chromosomal calmodulin $b_{2}, b_{1}$, or $a$ genes (whose sequences are virtually identical; Tschudi et al. 1985). The recombinant calmodulin locus of events $\mathrm{B}, \mathrm{C}$, and $\mathrm{D}$ therefore retains, $3^{\prime}$ to the $\mathrm{CNeoC}$ gene, the intact genomic calmodulin gene $c_{;}$genes $b_{2}$, and $c_{;}$or genes $b_{1}, b_{2}$ and $c$, respectively (Fig. 1B). Because the calmodulin probe hybridizes to each of the calmodulin gene copies, the diagnostic bands should become increasingly intense going from events $A$ to $B$ to $C$ to $D$, as is observed (Fig. 2B).

The organization of the recombined calmodulin locus of events A-D is supported further by the analogous mapping CIaI- plus SalI-digested DNA /see Fig. 5, below), which yields smaller fragments that can be sized more accurately. Cell lines of event A yielded a 2.5-kb calmodulin-containing fragment that comigrates with the equivalent fragment from $\mathrm{CNeoC}$ plasmid DNA

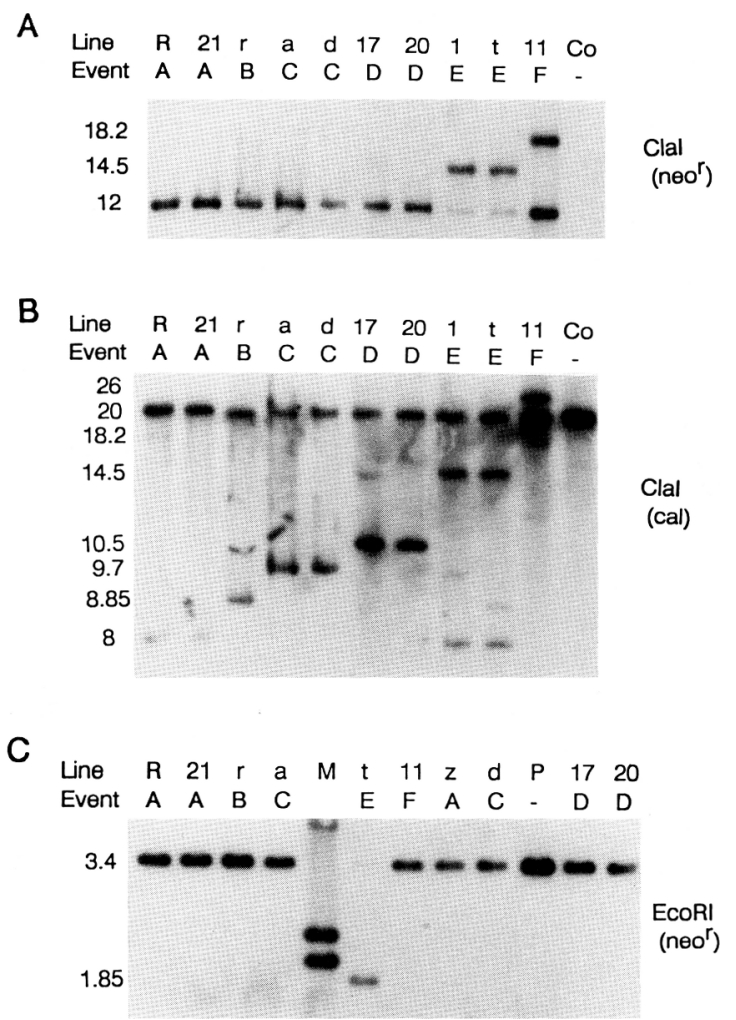

Figure 2. Analysis of the DNA organization of representative transfected cell lines. DNA from transformant cell lines of events A-F was cleaved with $\mathrm{ClaI}$ and hybridized first with the $n e o^{x}$ probe $(A)$ and then with the cal probe $(B)$ after complete stripping of the $n e o^{r}$ probe. Lane Co represents untransfected cellular DNA. $(C)$ Genomic DNA from lines representing the various events was cleaved with EcoRI and hybridized with the neo $o^{\mathrm{r}}$ probe. Lane $M$ shows size markers of HindIII-cleaved $\lambda$ DNA. Lane $P$ contains plasmid $\mathrm{CNeoC}$, cleaved with EcoRI. Sizes are shown in kilobases. The two cell lines shown for event $\mathrm{E}$ are not pure clones but also contain a small component of events $C$ and $B$, respectively. 
(data not shown), and the corresponding fragments from cell lines of events B, C, and D, indeed, show the $0.85-\mathrm{kb}$ progressive increase in size. Thus, the cell lines of events $\mathrm{A}-\mathrm{D}$ are as diagramed in Figure 1B.

\section{Cell lines of events $E$ and $F$}

Lines representing recombination event $E$ (lines 1 and $t$ ) showed calmodulin sequences on the same $8-\mathrm{kb} \mathrm{ClaI}$ fragment and the same $2.5-\mathrm{kb}$ ClaI-SalI fragment as those of event $\mathrm{A}$ (Figs. $2 \mathrm{~B}$ and $5 \mathrm{~A}$ ), indicating that their downstream recombination occurred within or downstream of the genomic calmodulin gene $\mathrm{c}$ (illustrated in Fig. 1B). However, their upstream recombination was different from that discussed above. Lines of event $\mathrm{E}$ have a $14.5-\mathrm{kb}$ neo ${ }^{\mathrm{x}}$-containing ClaI fragment, $2.5 \mathrm{~kb}$ larger than the analogous fragment from the other cell lines (Fig. 2A). This difference was confirmed by sizing SalI- and ClaI-digested DNA /which yielded a $5.5-\mathrm{kb}$ fragment from cell lines of event $E$ and a 3-kb fragment from the other lines; not shown|. The extra $2.5 \mathrm{~kb}$ represents three $0.85-\mathrm{kb}$ calmodulin gene repeats, as shown in Figure 1B, event E. This organization would result if the upstream recombination was within the $87 \mathrm{bp}$ surrounding the $5^{\prime}$ end of the $\mathrm{CNeoC}$ gene that is also present in the calmodulin $c$ gene (see Fig. 1B). As predicted, the cell lines of event $\mathrm{E}$ give a $1.85-\mathrm{kb} \mathrm{neo}^{\mathrm{r}}$-containing EcoRI fragment (the $1-\mathrm{kb}^{2} e^{\mathrm{x}}$ region plus a $0.85-$ $\mathrm{kb}$ calmodulin repeat) rather than the $3.4-\mathrm{kb} E c o \mathrm{RI}$ fragment (Fig. 2C) and 2.5- and 5.5-kb calmodulin-containing ClaI plus Sall fragments (see Fig. 5, below); this organization is confirmed in Figure 3 (see below).

Lines of event $\mathrm{F}$ have two copies of neo ${ }^{\mathrm{r}}$ sequences, yielding 12 - and $18.2-\mathrm{kb}$ ClaI fragments (Fig. 2A). The $12-\mathrm{kb}$ fragment comigrated with that of events A-D (Fig. $2 \mathrm{~A}$, as did the analogous 3 -kb SalI plus ClaI fragment; data not shown), indicating that the upstream recombination also took place within the $7.2-\mathrm{kb}$ region of homology upstream of the calmodulin-coding sequences.
The $\sim 18-\mathrm{kb} n e o^{\mathrm{r}}$-containing fragment of event $\mathrm{F}$ comigrated with linearized full-length CNeoC plasmid DNA (data not shown), indicating that more than one copy of the entire CNeoC plasmid integrated into the cellular genome. Reprobing this ClaI digest for calmodulin sequences showed the $\sim 18$-kb plasmid-size fragment and a $\sim 27$-kb fragment, as well as the 20 -kb fragment from the other calmodulin chromosomal locus (Fig. 2B, event F); the former two fragments were also detected upon reprobing for pBR322 vector sequences (data not shown). These data led to the structure for event $F$ (Fig. 1B) in which two copies of the entire $\mathrm{CNeoC}$ plasmid homologously inserted upstream of the calmodulin locus. As expected, this event resulted only when the transfecting CNeoC DNA was cleaved once within a region of homology, using $\mathrm{XbaI}$ (Fig. 1A).

Reprobing the filter of Figure 2, A and B, for pBR322 sequences showed that only cells of event $F$ contained them. This provides further evidence that event $F$ resulted from insertion of the whole transfecting plasmid but that the other cell lines arose from a double crossover surrounding the neo region, and therefore lack pBR322 sequences (Fig. 1A,B).

\section{Sequence of a junction derived by homologous recombination}

To confirm that the gene targeting of transfecting CNeoC DNA occurred by homologous recombination to the nucleotide, the junction region of cell line 1 (event $E$ ) was sequenced. We chose to analyze this junction because it occurs within an 87 -bp region (see above), while all other recombination events can be localized only to within $>420$ bp regions (Fig. 1B). This recombination junction was polymerase chain reaction (PCR)-amplified by using a $5^{\prime}$ primer of calmodulin-coding region and a $3^{\prime}$ primer for neor sequence (see diagram in Fig. 3). Dideoxy sequencing of the cloned junction showed that it begins in the $b_{2} / c$ intergenic calmodulin sequence, continues

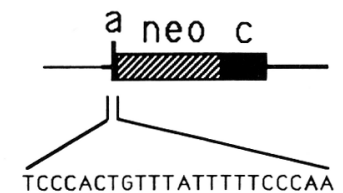

GTGTGAAGGAAAAAGGAAGGTA

AATAACATTGATAAGTAACATC

CACTTGATTTACGATGGCCGAT CAACTCTCCAACGAGCAGATCG

GATCAATGATTGAACAAGATGG

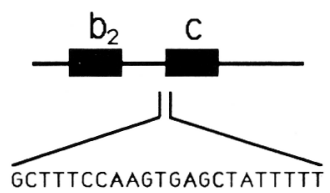

GTGTGAAGGAAAAAGGAAGGTA aATAACATTGATAAGTAACATC CACTTGATTTACGATGGCCGAT CAACTCTCCAACGAGCAGATCT CCGAATTCAAGGAGGCGTTCTC

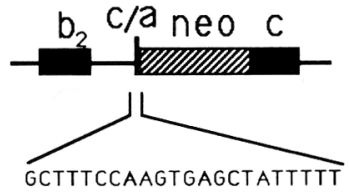

GTGTGAAGGAAAAAGGAAGGTA AATAACATTGATAAGTAACATC CACTTGATTTACGATGGCCGAT CAACTCTCCAACGAGCAGATCG

GATCAATGATTGAACAAGATGG

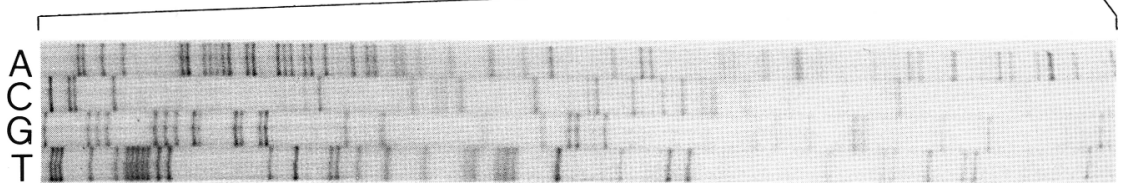

Figure 3. Integration of the $\mathrm{CNeoC}$ gene by homologous recombination. The diagrams at the top depict the transfecting $\mathrm{CNeoC}$ gene (left), the $b_{2}$ and $c$ wild-type calmodulin gene region (center), and the region surrounding the integrated neor gene of event E, cell line 1 (right). (Below) The sequence of the indicated region surrounding the 5' end of the CNeoC gene (left; Eid and Sollner-Webb 1991), the wild-type calmodulin $c$ gene (center; Beck et al. 1982), and the $n e o^{r}$ gene of cell line 1, event E (right). The dideoxy sequence analysis of this region of cell line 1 is shown at the bottom. The $87-\mathrm{bp}$ region contained in all three of the sequences is indicated by underlining; it includes the first 57 bp upstream of the translation initiation codon (Tschudi et al. 1985) and the first $30 \mathrm{bp}$ of the common coding region (Eid and Sollner-Webb 1991). Double underlining represents the ATG calmodulin translation initiation codon. The sequence of cell line 1 , event $\mathrm{E}$, is identical to that of the genomic calmodulin locus upstream of the common region and identical to that of the $\mathrm{CNeoC}$ gene downstream of the common region. 
into the 87-bp homologous sequence, and extends into the $n e o^{\mathrm{r}}$ sequence (Fig. 3), thereby verifying that cell line 1 results from a homologous recombination event (Figs. $1 \mathrm{~B}$ and 31 .

The number of functional calmodulin genes affects the growth rate of $\mathrm{T}$. brucei

While propagating the cell lines, those representing event A (replacement of all four calmodulin genes of the targeted locus) were consistently less dense than the other cell lines and only reached a lower density $\left(\sim 1 \times 10^{7}\right.$ vs. $\sim 2 \times 10^{7}$ cells $\left./ \mathrm{ml}\right)$. To measure growth rate, $\log$-phase cultures representing all of the recombination events, as well as control untransfected cells, were diluted to equal concentration and grown in medium lacking G418. From cell counts, growth rates were calculated and compared with that of the untransfected cells (Fig. 4). Figure 4 represents at least three different experiments of at least two different cell lines for each event (except event B with only one existent cell line). The lines of event A consistently grew at only $40-50 \%$ the rate of untransfected cells. In constrast, those of event $B$, with only one extra calmodulin gene, generally grew like the untransfected cells. Thus, cell growth is impaired in lines bearing four intact calmodulin genes

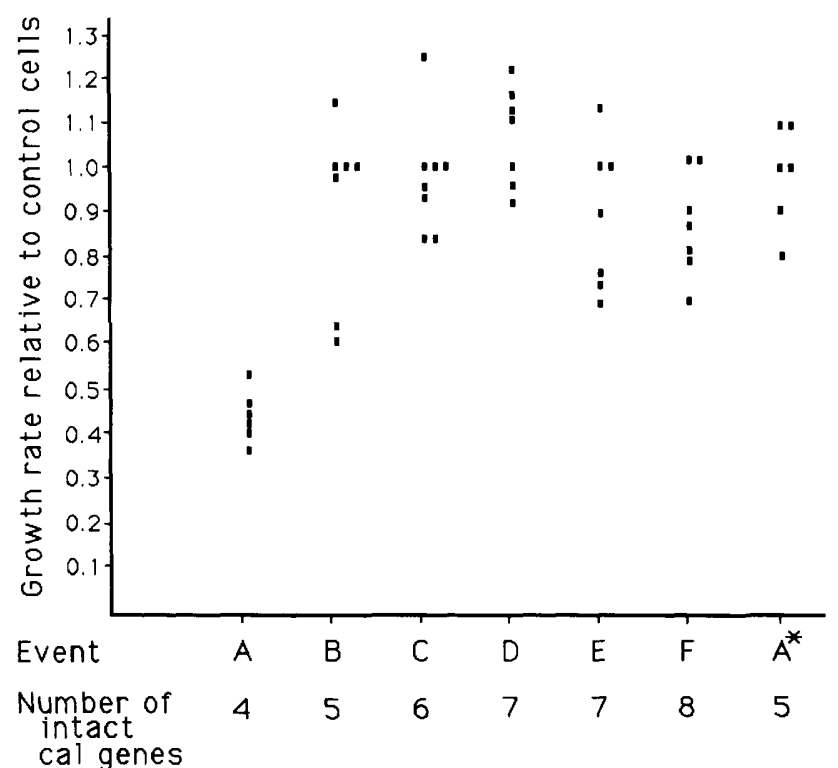

Figure 4. Correlation of growth rate with the number of intact calmodulin genes in the transformant cell lines. The growth rate of various tranformants of events $A-F$, relative to that of control untransformed $T$. brucei grown in parallel, is plotted. The growth rates were consistent throughout the logarithmic growth period. Data for lines of event A were obtained prior to any evidence of altered genotype (i.e., on or prior to August 9, 1990 for line 21; see Fig. 5 C). $A^{\star}$ represents the derivatives of event $A$, lines $R$ and 21 , after acquisition of an additional calmodulin gene copy on the nontargeted chromosome and reversion to normal growth rate (measured on or after November 23, 1990; see Fig. 5A). The other cell lines of event A also reverted to normal growth rate but through different genetic alterations. but is virtually wild type in lines bearing five or more calmodulin genes.

The slow-growing cell lines phenotypically revert, often by duplicating a calmodulin gene in the untargeted chromosome

The transformed cell lines have been passaged continuously for over 1 year, and their growth rates and DNA organizations have been monitored. The growth rates of the cell lines shown to be event A, 40-50\% of the untransfected cells when initially analyzed (Fig. 4), began to increase over subsequent months, until they eventually became indistinguishable from the untransfected cells (Fig. 4, column $\mathrm{A}^{*}$ and data not shown). The growth rates of cell lines containing five or more intact calmodulin genes remained constant.

Over the months, a corresponding change in the digestion patterns of the DNA from the cell lines of event $A$ was also observed. DNA cleaved at early times with ClaI and SalI, and analyzed with the calmodulin probe, showed the same 7-kb fragment representing the untargeted calmodulin locus that is obtained from all of the cell lines (Fig. 5C). However, this $7-\mathrm{kb}$ fragment began to disappear from the DNA of cell line 21, when prepared 2 months later (Fig. 5B) and was virtually absent from DNA prepared 3.5 months later (Fig. 5A). Concomitantly, a 7.8-7.9-kb fragment appeared (Fig. 5A,B; fragments sized from semi-log plots of the data of Fig. 5). Cell line $\mathrm{R}$ (another event $\mathrm{A}$ ) also showed a transition from the $7-\mathrm{kb}$ to the $\sim 7.85-\mathrm{kb}$ fragment (Fig. $5 \mathrm{~A}$ ). Thus, the calmodulin locus of the untargeted chromosome mutated, becoming larger by the size of one $(0.85 \mathrm{~kb})$ calmodulin gene repeat. Further probing of this new $\sim 7.85$ $\mathrm{kb}$ fragment revealed that it contained neither $n e o^{\mathrm{r}}$ nor pBR322 sequences (data not shown). Proof that the $\sim 0.85$ $\mathrm{kb}$ increase in the size of this fragment was the result of an increase from four to five copies of the calmodulin gene repeat came from comparing EcoRI-cleaved DNA of cell lines $\mathrm{R}$ and 21 with that of untransfected cells (repeating the experiment of Fig. $2 \mathrm{C}$, but probing for the entire region contained in the $7-\mathrm{kb}$ genomic Sall fragment). As expected, four fragments were observed (the $0.85-\mathrm{kb}$ calmodulin repeat, the 12 - $\mathrm{kb} 3^{\prime}$-flanking region, and the 2.4- and 3.4-kb 5'-flanking regions from the two chromosomes; Fig. 1; data not shown). If the 0.85-kb insertion had resulted from any rearrangement other than a duplicated calmodulin gene repeat, a new fragment of a different size would have been observed.

Notably, the acquisition of the extra calmodulin gene by the cell lines forming event $A^{*}$ occurred coincident with their reversion to wild-type growth rate. Evidently, their growth rate was increased by the duplication of one of the four calmodulin gene copies on the chromosome that had not received the neor gene. The loss of the parental 7-kb fragment in event $A^{\star}$ also confirms that the calmodulin locus was diploid in the original $T$. brucei cells.

In conjunction with their regaining wild-type growth rate, the other cell lines of event $\mathrm{A}$ also changed their 

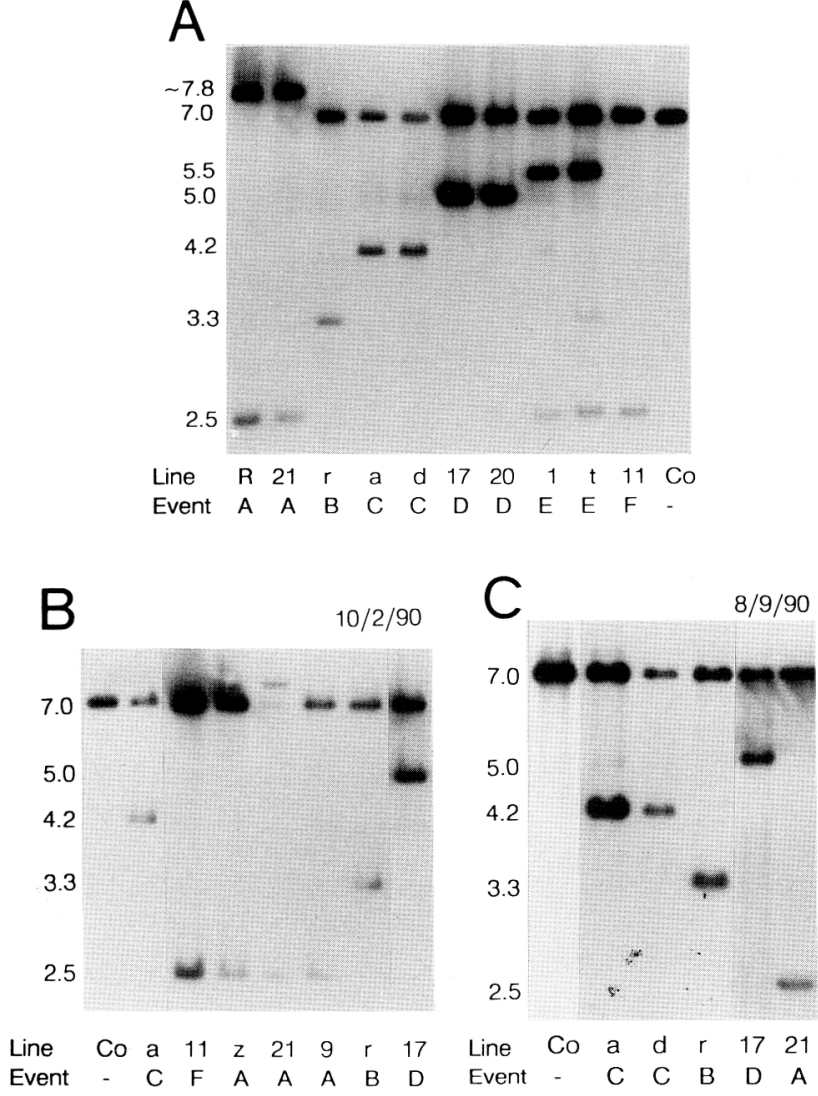

Figure 5. Analysis of DNA from transfected cell lines prepared after different time periods of propagation. Genomic DNA from the indicated cell lines was cleaved with SaII and ClaI and was detected with the cal probe. The dates of DNA preparation are shown (month/date/year). The transfections took place in January, 1990; but because of the low cell density inherent in the cloning protocol, rapid growth did not commence for 4-5 months. (Lane Co) DNA of untransfected control T. brucei.

genotype, resulting in new examples of events C, D, and E. In these cases, however, it is not possible to be certain that the extra calmodulin gene arose by gene duplication, rather than by overgrowth of a contaminating cell representing event C, D, or E. Nonetheless, it is clear that while cell lines of events B-E remained relatively stable over time, those of event A altered their genotype to acquire a wild-type growth rate.

\section{Transcripts of the neo ${ }^{T}$ gene in transfected cells}

Because the tranfected cell lines were selected for growth in the presence of G418, it was expected that they make $n e o^{\mathrm{r}}$ mRNA. This was confirmed by Northern blotting and probing for $n e o^{\mathrm{x}}$ sequences (Fig. 6). Notably, cell lines of events $\mathrm{A}, \mathrm{E}$, and $\mathrm{F}$ generated $\sim 2.1-\mathrm{kb} n e o^{\mathrm{r}} \mathrm{RNA}$, while lines of events $\mathrm{B}, \mathrm{C}$, and D generated $\sim 1.8-\mathrm{kb} \mathrm{neo}{ }^{\mathrm{r}}$ RNA. These sizes are as predicted from the structure shown in Figure 1B. In events $\mathrm{A}, \mathrm{E}$, and $\mathrm{F}$, the $n e \mathrm{o}^{\mathrm{r}}$ containing transcripts extend into the calmodulin $c$ gene and should end at its poly(A) site, whereas in events $B, C$, and $\mathrm{D}$ they should extend into the calmodulin $b_{2}, b_{1}$, and $a$ genes, respectively, and use their poly(A) addition sites. It has been shown previously that the natural calmodulin $c$ gene yields $\mathrm{a} \sim 1.1-\mathrm{kb}$ transcript while the natural calmodulin $a$ and $b$ genes yield $\sim 0.8$-kb transcripts (Tschudi et al. 1985; Tschudi and Ullu 1988). Thus, the presence of the inserted $1-\mathrm{kb} n e o^{\mathrm{r}}$ segment should increase their lengths to $\sim 2.1$ and $\sim 1.8 \mathrm{~kb}$, respectively, as is observed (Fig. 6). This also suggests that the inserted $n e o^{\mathrm{r}}$ sequences do not interfere with either normal $5^{\prime}$ or normal 3' RNA end formation that is directed by the upstream and downstream calmodulin sequences, respectively.

\section{Discussion}

\section{Homologous recombination events in $\mathrm{T}$. brucei}

We have studied transformation of $T$. brucei using a calmodulin-neomycin-resistance fusion gene $(\mathrm{CNeoC})$ and found that all of the resultant neomycin-resistant cell lines arose from targeting of the exogenous DNA to the homologous calmodulin locus of the host chromosome (Fig. 1B; Table 1). Restriction mapping indicated that homologous recombination was responsible for the gene targeting in all of the cell lines (Fig. 2), and sequencing the junction of one common transformant demonstrated that the recombination, indeed, was homologous to the nucleotide (Fig. 3).

Notably, the transformants show several different recombination patterns (Fig. 1B). This occurs because the calmodulin gene, like most genes in T. brucei (Michels et al. 1986), is present in multiple tandem copies (Tschudi et al. 1985); the recipient cell line used in our studies has four copies at both chromosomal loci (Eid and Sollner-Webb 1991). Thus, the CNeoC DNA can recombine with the genome in more than one way, either by using only the $>7 \mathrm{~kb}$ and $6 \mathrm{~kb}$ of $5^{\prime}$ and $3^{\prime}$ calmodulinflanking sequence present in the $\mathrm{CNeoC}$ plasmid or by also using the calmodulin gene sequence surrounding the neor sequence, which can recombine with any of the chromosomal calmodulin genes. Thus, double crossovers can result in the loss of one, two, three, or all four of the intact calmodulin genes from the recipient chromosomal locus (Fig. 1B). In addition, $\mathrm{CNeoC}$ insertion can result from integration of the entire plasmid, without a corresponding loss of chromosomal sequences.

Transformants were obtained by using CNeoC DNA that was singly cleaved to generate large $5^{\prime}$ - or $3^{\prime}$-flanking regions of homology or doubly cleaved to excise the $\mathrm{CNeoC}$ region. In all cases, the vast majority of the transformants were substitution type, presumably re-

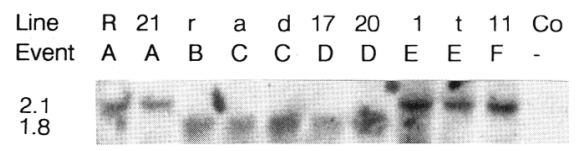

Figure 6. Analysis of RNA from transfected cell lines. Total cellular RNA was electrophorectically resolved and detected by using the neo $o^{\mathrm{r}}$ probe. (Lane Co) RNA from control, untransfected $T$. brucei. 
sulting from double crossovers. In all 31 of these, at least one of the crossovers took place in the large homologous region abutting the linearized end of the transfecting DNA. Unexpectedly, however, the second crossover generally was not in the large homologous region on the other side of the $n e o^{\mathrm{r}}$ gene (event $\mathrm{A}$ ) but in the smaller homologous regions of calmodulin gene sequence (events B-E). All of the cell lines of events B, C, and D (with the terminal crossover in the 5'-flanking homology region) were obtained by using CNeoC DNA cleaved in the 5'-flanking region (with $X b a \mathrm{I}$ ), whereas none were obtained by using DNA cleaved only in the 3 '-flanking region; all cell lines of event $\mathrm{E}$ (with the terminal crossover in the $3^{\prime}$-flanking homology region) derived from CNeoC DNA that was cleaved in the $3^{\prime}$-flanking region (with NotI) and none derived from DNA cleaved only in the 5 '-flanking region (Fig. 1B; Table 1). These results indicate that the initial recombination event is directed by an end of the linearized transfecting DNA, that it takes place within the adjoining region of chromosomal homology, and that it is not directed to an appreciable extent by homologous regions not juxtaposed to a cleaved end. Thus, the initial recombination event in trypanosomes appears similar to that in yeast (Hinnen et al. 1978; Orr-Weaver et al. 1981) and mammals (Thomas and Capecchi 1987). The efficiency of this first crossover event also appears to be dependent on the length of the homologous region abutting the cleaved end, because one attempt at transfection of CNeoC DNA in which both the $5^{\prime}$ - and $3^{\prime}$-terminal homologous regions were shortened to $\sim 2 \mathrm{~kb}$ (by Sall cleavage) yielded no transformants (J. Eid and B. Sollner-Webb, unpubl.).

The second recombinational event of the $T$. brucei double crossovers is evidently governed by different rules than the first. Only infrequently is it in the other large $(6-7 \mathrm{~kb})$ homologous region of calmodulin-flanking sequence (event A, Fig. 1B), as might have been expected from precedents in mammalian systems (Thomas and Capecchi 1987). The second recombination event occurs most frequently in the shorter calmodulin gene regions, a 420-bp target for events B, C, and D and an 87-bp target for event $\mathrm{E}$ (Fig. 1B). Notably, proximity to the homologous region utilized for the first crossover is a major determinant for the second event. This is illustrated by the fact that five of seven transformants resulting from NotIcleaved $\mathrm{CNeoC}$ had their second crossover in the most proximal 87-bp calmodulin segment (of the calmodulin $c$ gene; Fig. $1 \mathrm{~B}$, event $\mathrm{E}$ ), none used the more distal calmodulin $b_{1}$ or $b_{2}$ segments, and only two had their second crossover in the entire $6 \mathrm{~kb}$ of $3^{\prime}$-flanking homology region (Table 1). A qualitatively similar situation was observed with $X b a I$-cleaved transfecting DNA, where event $D$ is favored over event $C$, which is favored over event $B$ (Fig. 1B; Table 1). This preference for the second recombination event occurring close to the first is especially striking with the doubly cleaved DNA, where none of the seven resultant cell lines had their second crossover in the other large region of flanking homology, even though it abuts a linearized end that is recombinogenic in the first crossover event.
When the transfecting DNA was singly cleaved within the $5^{\prime}$ region of homology ( $\mathrm{XbaI}$ cleaved; Fig. $1 \mathrm{~A}$ ), plasmid insertions were also obtained (event F). As expected, such insertions were not similarly generated from CNeoC DNA cleaved at the end of a region of homology (NotI) or doubly cleaved (XbaI and NotI). Notably, however, plasmid insertions only account for 2 of the 12 transformants analyzed from XbaI-cleaved DNA (Table 1). This is unlike the situation in yeast and mammalian cells, where plasmids linearized within a region of homology yield primarily insertion-type transformants (Orr-Weaver et al. 1981; Thomas and Capecchi 1987).

Both cell lines representing the insertion event contain two complete copies of the transfecting plasmid (event F; Fig. 1B), as shown by electrophoretic analyses performed 6 months or more after the transfection date (Fig. 2A,B; data not shown). However, analysis of DNA extracted a shorter time after the transfection indicated that both cell lines originated as single-insertion events which, over time, changed to double insertions /data not shown). This might be the result of subsequent unequal crossing-over, facilitated by the $13 \mathrm{~kb}$ of duplicated calmodulin sequence flanking the $n e o^{x}$ gene in the single insertions, and selection of these cells during continuous growth in G418.

\section{$\mathrm{T}$. brucei requires reiterated calmodulin genes}

Unlike the situation in most eukaryotes where genes are typically present in a single copy per haploid chromosome complement, in trypanosomatids genes generally occur in multiple tandem copies (Thomashow et al. 1983; Clayton 1985; Tschudi et al. 1985; Michels et al. 1986; Dragon et al. 1987). It has been speculated that these duplicated copies may be necessary to obtain sufficient quantities of essential RNAs from the gene expression machinery of trypanosomes. The process of gene expression in trypanosomes is still largely uncharacterized, but evidently differs from most other eukaryotes in a number of ways, any of which could affect the efficiency of gene expression in these primitive organisms. For example, trypanosome RNAs appear to be initially transcribed in a polycistronic fashion from still unknown but distant promoters and then cleaved to monocistronic RNAs in a process involving the transsplicing of a common leader sequence as well as a polyadenylation directed by noncanonical sequences (Thomashow et al. 1983; Clayton 1985; Gonzalez et al. 1985; Tschudi et al. 1985; Michels et al. 1986; Murphy et al. 1986; Sutton and Boothroyd 1986; Dragon et al. 1987).

The calmodulin gene is a typical tandemly repeated $T$. brucei gene. It encodes the calcium-binding protein calmodulin, which in other organisms is required for numerous essential functions, such as cell-cycle progression (Chafouleas et al. 1982), signal transduction (Braam and Davis 1990), microtubule assembly (Charles et al. 1983), cell motility, cyclic nucleotide metabolism, and protein phosphorylation (for review, see Wang and Weissman 1979). It is a unique gene in yeast (Davis et al. 
1986; Takeda and Yamamoto 1987), Aspergillus (Rasmussen et al. 1990), and Drosophila (Smith et al. 1987) but is present in three tandem copies at both chromosomal loci in many strains of $T$. brucei (Tschudi et al. 1985) and in four tandem copies in other strains (Tschudi and Ullu 1988), including the one used in our studies (see above). Transformation of this strain by CNeoC DNA results in deletion of up to four of the eight copies of the chromosomal calmodulin genes. Notably, lines with only four remaining intact calmodulin genes-twothirds of the normal calmodulin gene complement of other natural $T$. brucei strains-grow at about half the wild-type rate (event A; Fig. 4). Even though the multiple calmodulin genes evidently are all expressed (Tschudi et al. 1985), four gene copies are insufficient to support normal growth. In contrast, lines with five or more calmodulin gene copies show no growth phenotype, whether the additional gene is present on the same chromosomal locus that contains the neo gene or on the other chromosome (lines B and $\mathrm{A}^{*}$, respectively; Fig. 4). These data provide the first evidence that we are aware of demonstrating a requirement for the naturally duplicated copies of a $T$. brucei gene.

Strikingly, upon continued propagation, the cell lines of event $A$, in which four of the natural calmodulin genes had been deleted, gradually reverted to wild-type growth rate (Fig. 4). These phenotypic changes were all accompanied by genotypic changes (Fig. 5). In some lines, this was a duplication event in the calmodulin locus that had not recombined with the transfecting DNA, increasing the number of tandem calmodulin gene copies from four to five (lines $\mathrm{R}$ and 21, Fig. 5; event $\mathrm{A}^{*}$, Fig. 4). This is assuredly a compensatory mutation, for five tandem calmodulin gene copies are not found in the starting T. bru$c e i$ strain. Other original cell lines of event $\mathrm{A}$ reverted to normal growth rate by changing to events $\mathrm{C}-\mathrm{E}$ /data not shown), either by an interchromosomal gene duplication or by overgrowth of a contaminating cell. None of the original seven cell lines of event A remained unchanged after a year of propagation, although those of events B-E were stable. These data provide strong evidence for a causal relationship between the increased calmodulin gene number and the restored growth rate experienced by the cell lines of event $A$.

The compensatory mutations described above for the number of $T$. brucei calmodulin genes could be similar to the bobbed mutation in Drosophila, where lines lacking more than half of their rRNA genes duplicate remaining copies by unequal crossing-over to regain normal phenotype (Tartoff 1973, 1974; Franz and Kunz 1981). There are numerous other examples where gene number increases under selective pressure /Stark and Wahl 1984), including the dihydrofolate reductase (DHFR) gene of mammals (Alt et al. 1978) and Leishmania tropica (Corderre et al. 1983) and the glyS gene of Salmonella typhimurium (Straus and Straus 1976). There is reason to suspect (Straus and Straus 1976) that the same cellular machinery is involved in this gene duplication and the original homologous recombination event that generated the gene deletion.
In conclusion, the ability to target $T$. brucei genes for recombination, to observe the effect of this on cellular function, and to select and study revertants of such changes should be of great value in further understanding the unusual molecular processes of this interesting organism. In particular, the observation that a growth phenotype results from reducing the number of calmodulin genes to one-half the normal chromosomal complement offers promise that analogous deletion of one of the two allelic sets of other genes will similarly show a phenotype, permitting a study of the effect of $T$. brucei genes without necessitating the mutation of both chromosomal loci.

\section{Materials and methods}

Cell lines

Procyclic $T$. brucei cultures (strain TREU 667) were stably transformed by electroporation with the $\mathrm{CNeoC}$ plasmid, cleaved with XbaI and NotI (Eid and Sollner-Webb 1991) or with $X b a I$ or NotI alone (see Fig. 1A). The $18-\mathrm{kb}$ pBR322-based CNeoC plasmid contains $7.2 \mathrm{~kb}$ upstream of the $T$. brucei calmodulin gene cluster and the first 30 nucleotides beyond the translation start site of the calmodulin $a$ gene, a $1-\mathrm{kb}$ segment from pSV2neo containing the neomycin phosphotransferase gene (Beck et al. 1982) inserted in-frame, the last $420 \mathrm{bp}$ of the coding region of the calmodulin $c$ gene, and $5.6 \mathrm{~kb}$ of 3 '-flanking sequence (Eid and Sollner-Webb 1991; see Fig. 1A). All transformants have been maintained for the past year in regular growth medium supplemented with $30 \mu \mathrm{g} / \mathrm{ml}$ of G418 (Eid and SollnerWebb 1991). To measure growth rates, logarithmic phase cells were seeded at $2 \times 10^{6}$ cells $/ \mathrm{ml}$ in regular medium without G418 and cell density was measured every 2 days /doubling time $\sim 24 \mathrm{hr}$.

\section{DNA and RNA analyses and hybridrization probes}

Preparation of genomic DNA and total cellular RNA and their analysis by agarose gel electrophoresis and Southern and Northern transfers, were described previously (Eid and Sollner-Webb 1991). The neo ${ }^{\mathrm{r}}$ probe (Fig. 1B) is the 1.3-kb HindIII-AvaI fragment of pSV2neo (Beck et al. 1982) containing the coding region of the neomycin-resistance gene. The calmodulin-coding region probe (cal; Fig. 1B) is the 450-bp EcoRI-HindIII fragment from the genomic calmodulin genes (also present in the $\mathrm{CNeoC} \mathrm{fu-}$ sion gene), which contains the bulk of the calmodulin-coding region (Tschudi et al. 1985). The pBR probe (Fig. 1B) is the 2.3-kb EcoRI-PvulI fragment from pBR322, which corresponds to the vector sequences of the CNeoC plasmid (Eid and Sollner-Webb 1991).

\section{Primers, PCR, and DNA sequencing}

The region of the recombination junction of transformant line 1 (event E) was cloned following PCR amplification of total genomic DNA by standard methods (Saiki 1990). The 3' primer (5'CCGGATCCGGCCCAAGCGGCCGGAGAACCTGC-3') is complementary to a $5^{\prime}$ region of the $n e o^{\mathrm{r}}$ sequence (Beck et al. 1982); the 5' primer (5'-CCGAATTCGGCCACGAGGCTGACATTGATGG-3') corresponds to a $3^{\prime}$ portion of the calmodulin-coding region (Tschudi et al. 1985). This allows amplifica- 
tion of the region between the $b_{2}$ gene and the neomycin gene (event $E_{\text {; Fig. }}$ 1B). The PCR product was cleaved at the EcoRI and $B a m H I$ sites present in the $5^{\prime}$ and $3^{\prime}$ primer sequences, respectively, and was cloned in EcoRI-BamHI-digested M13 phage for dideoxy sequencing (Sambrook et al. 1989).

\section{Acknowledgments}

We thank Jef Boeke, Ed Mougey, Ken Piller, Karen Chapman, and Paul Englund for helpful discussions; and Ms. Linda Miller for assistance in preparation of the manuscript. This work was supported by grant GM34231 from the National Institutes of Health. J.E. was supported by the MacArthur Foundation.

The publication costs of this article were defrayed in part by payment of page charges. This article must therefore be hereby marked "advertisement" in accordance with 18 USC section 1734 solely to indicate this fact.

\section{References}

Alt, F., R. Kellems, J.R. Bertino, and R.T. Schimke. 1978. Selective multiplication of dihydrofolate reductase genes in methotrexate-resistant variants of cultured murine cells. $J$. Biol. Chem. 253: 1357-1370.

Beck, E., G. Ludwig, E.A. Auerswald, B. Reiss, and H. Schaller. 1982. Nucleotide sequence and exact localization of the neomycin phosphotransferase gene from transposon Tn5. Gene 19: 327-336.

Braam J. and R.W. Davis. 1990. Rain-, wind-, and touch-induced expression of calmodulin and calmodulin-related genes in Arabidopsis. Cell 60: 357-364.

Chafouleas, J.G., W.E. Bolton, H. Hidaka, A.E. Boyd III, and A.R. Means. 1982. Calmodulin and the cell cycle: Involvement in regulation of cell-cycle progression. Cell 28: 41-50.

Charles, K., M. Dipaola, F.R. Maxfield, and M.L. Shelanski. 1983. Microinjection of $\mathrm{Ca}^{++}$-calmodulin causes a localized depolymerization of microtubles. I. Cell Biol. 97: 19181924.

Clayton, C.E. 1985. Structure and regulated expression of genes encoding fructose biphosphate aldolase in Trypanosoma brucei. EMBO J. 4: 2997-3003.

Corderre, J.A., S.M. Beverly, R.T. Schimke, and D.V. Santi. 1983. Overproduction of a bifunctional thymidylate synthetase dihydrofolate reductase and DNA amplification in methotrexate resistant Leishmania tropica. Proc. Natl. Acad. Sci. 80: 2132-2136.

Cruz, A. and S.M. Beverly. 1990. Gene replacement in parasite protozoa. Nature 348: 171-173.

Davis, T.N., M.S. Urdean, F.R. Masiarz, and J. Thorner 1986. Isolation of the yeast calmodulin gene calmodulin is an essential protein. Cell 47: 423-431.

Dragon, E.A., S.R. Sias, E.A. Kato, and J.D. Gabe. 1987. The genome of Trypanosoma cruzi contains a constitutively expressed, tandemly arranged multicopy gene homologous to a major heat shock protein. Mol. Cell. Biol. 7: 1271-1275.

Eid, J. and B. Sollner-Webb. 1991. Stable transformation of Trypanosoma brucei that occurs exclusively by homologous recombination. Proc. Nat1. Acad. Sci. 88: 2118- 2121.

Franz, G. and W. Kunz. 1981. Intervening sequences in ribosomal RNA genes and bobbed phenotype in Drosophila hydei. Nature 292: 638-640.

Gonzalez, A, T.J. Lerner, M. Huecas, B. Sosa-Pineda, N. Noruiera, and P.M. Lizardi. 1985. Apparent generation of a segmental mRNA from two separate tandem gene families in Trypanosoma brucei. Nucleic Acids Res. 13: 5789-5804.
Hinnen, A., J.B. Hicks, and G.R. Fink. 1978. Transformation of yeast. Proc. Natl. Acad. Sci. 75: 1929-1933.

Lee, M.G.-S and L.H.T. Van der Ploeg. 1990. Homologous recombination and stable transfection in the parasitic protozoan Trypanosoma brucei. Science 250: 1583-1586.

Michels, P.A.M., A. Poliszczak, K.A. Osinga, O. Misset, J. Van Beeumen, R.K. Wierenga, P. Borst, and F.R. Opperdoes. 1986. Two tandemly linked identical genes code for the glycosomal glyceraldehyde-phosphate dehydrogenase in Trypanosoma brucei. EMBO J. 5: 1049-1056.

Murphy, W.J., K.P. Watkins, and N. Agabian. 1986. Identification of a novel $\mathrm{Y}$ branch structure as an intermediate in trypanosome mRNA processing: Evidence for trans splicing. Cell 47: 517-525.

Orr-Weaver, T.L., J.W. Szostak, and R.J. Rothstein. 1981. Yeast transformation: A model system for the study of recombination. Proc. Natl. Acad. Sci. 78: 6354-6358.

Rasmussen, C.D., R.L. Means, K.P. Lu, G.S. May, and A.R. Means. 1990. Characterization and expression of the unique calmodulin gene of Aspergillus nidulans. I. Biol. Chem. 265: 13767-13775.

Saiki, R.K. 1990. Amplification of genomic DNA. In PCR protocols and a guide to methods and applications (ed. M.A. Innis, D.H. Gelfand, J.J. Sninsky, and T.J. White), pp. 13-20. Academic Press, San Diego, CA.

Sambrook, J., E. Fritsch, and T. Maniatis. 1989. Molecular cloning: A laboratory manual, pp. 13.3-13.23. Cold Spring Harbor Laboratory Press, Cold Spring Harbor, New York.

Smith, V.L., K.E. Doyle, J.F. Maune, R.P. Munjaal, and K. Beckingham. 1987. Structure and sequence of the Drosophila melanogaster calmodulin gene. J. Mol. Biol. 3: 471-485.

Stark, G.R. and G.M. Wahl. 1984. Gene amplification. Annu. Rev. Biochem. 53: 447-491.

Straus, D.S. and L.D. Straus. 1976. Large overlapping tandem genetic duplications in Salmonella typhimurium. I. Mol. Biol. 103: 143-153.

Sutton, R. and J. Boothroyd. 1986. Evidence for trans splicing in trypanosomes. Cell 47: 517-523.

Takeda, T. and M. Yamamoto. 1987. Analysis and in vivo disruption of the gene coding for calmodulin in Schizosaccharomyces pombe. Proc. Natl. Acad. Sci. 84: 3580-3584.

Tartoff, K.D. 1973. Regulation of ribosomal RNA gene multiplicity in Drosophila melanogaster. Genetics 73: 57-71.

- 1974. Unequal mitotic sister chromatid exchange as the mechanism of ribosoinal RNA gene magnification. Proc. Natl. Acad. Sci. 71: 1272-1276.

Ten Ashroek, A.L.M.A, M. Ouellette, and P. Borst. 1990. Targeted insertion of the neomycin phosphotransferase gene into the tubulin gene cluster of Trypanosoma brucei. Nature 348: 174-175.

Thomas, K.R. and M.R. Capecchi. 1987. Site-directed mutagenesis by gene targeting in mouse embryo-derived stem cells. Cell 51: 503-512.

Thomashow, L.S., M. Milhausen, W.J. Rutter, and N. Agabian. 1983. Tubulin genes are tandemly linked and clustered in the genome of Trypanosoma brucei. Cell 32: 35-43.

Tschudi, C. and E. Ullu. 1988. Polygene transcripts are precursor to calmodulin mRNAs in trypanosomes. EMBO $J$. 7: 455-463.

Tschudi, C., A.S. Young, L. Ruben, C.L. Patton, and F.F. Richards. 1985. Calmodulin genes in trypanosomes are tandemly repeated and produce multiple mRNAs with a common $5^{\prime}$ leader sequence. Proc. Natl. Acad. Sci. 82: 3998-4002.

Wang, J.H. and D.M. Weissman. 1979. Calmodulin and its role in the second-messenger system. Curr. Topics Cell Regul. 15: $47-107$. 


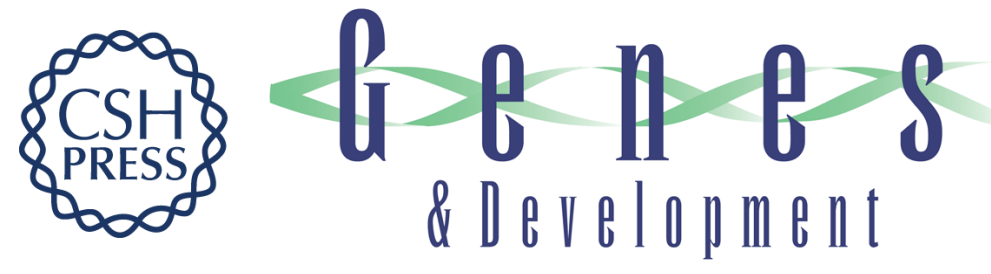

\title{
Homologous recombination in the tandem calmodulin genes of Trypanosoma brucei yields multiple products: compensation for deleterious deletions by gene amplification.
}

\author{
J E Eid and B Sollner-Webb
}

Genes Dev. 1991, 5:

Access the most recent version at doi:10.1101/gad.5.11.2024

$\begin{array}{ll}\text { References } & \begin{array}{l}\text { This article cites } 32 \text { articles, } 12 \text { of which can be accessed free at: } \\ \text { http://genesdev.cshlp.org/content/5/11/2024.full.html\#ref-list-1 }\end{array}\end{array}$

\section{License}

Email Alerting Service

Receive free email alerts when new articles cite this article - sign up in the box at the top right corner of the article or click here.

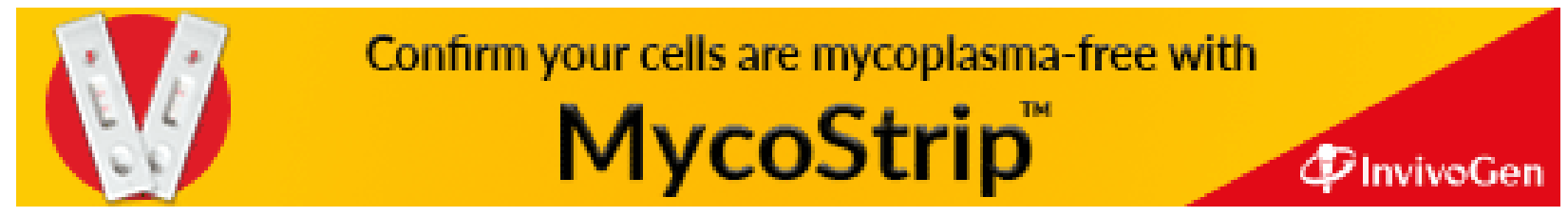

